\title{
The fatty acid composition and properties of oil extracted from cotton (Gossypium herbaceum) seed of Bangladesh
}

\author{
S. K. Roy ${ }^{a}$, S. M. M. Karim, ${ }^{b}$ Z. Rahman ${ }^{a}$, S. Aziz ${ }^{a} *$ and S. M. M. Hassan ${ }^{a}$, \\ ${ }^{a}$ Chemical Research Division, Bangladesh Council of Scientific and Industrial Research, \\ Dhanmondi, Dhaka-1205, Bangladesh and bepartment of Chemistry, Jagannath University, Dhaka.
}

\begin{abstract}
Gossypium herbaceum (cotton) seed oil was investigated to determine the fatty acid composition and proximate analyses. The seed contains $15.0 \%$ of fatty oil. The saturated and unsaturated fatty acid each comprises $21.73 \%$ and $78.27 \%$, respectively, of the oil. The percent composition of the extracted oil was identified by gas liquid chromatography. Among the identified fatty acid oleic acid contributed to the highest proportion (29.40)\%, where as palmitic acid, stearic acid, linoleic acid and ecosenoic acid combinedly contributed to the rest $70.60 \%$. Proximate analysis showed that Gossypium herbaceum seed could be considered as a good source of oleic acid as well as it can be treated as edible oil (after refining). By removing gossypol, a toxic yellow polyphenolic compound produced by cotton and other members of the order Malvaceae, it can be considered as an edible oil. Activated charcoal can be used in this purpose.
\end{abstract}

Key words: Gossypium herbaceum, Fresh cotton seed oil, Fatty acid composition, Palmitic acid, Oleic acid, Gas liquid chromatography

\section{Introduction}

Cotton seed oil is a cooking oil extracted from the seeds of cotton plant of various species, mainly Gossypium hirsutum and Gossypium herbaceum. Cotton grown for oil extraction is one of the big four genetically modified crops grown around the world, next to soy, corn, and rapeseed (canola) (Anonymous, 2009). The cotton seed has a similar structure to those of other oilseed such as sunflower seed, having an oil bearing kernel surrounded by a hard outer hull; in processing, the oil is extracted from the kernel. Cotton seed oil is used for salad oil, mayonnaise, salad dressing, and similar products because of its flavor stability (Richard et al., 2005). The cotton seed oil undergoes intensive treatment after extraction to reduce the level of gossypol found in untreated cotton seed oil, the consumption of which may produce undesirable side-effects (Coutinho, 2002). Its fatty acid profile generally consists of $70 \%$ unsaturated fatty acids including 18\% (13\% - 44\%) monounsaturated (oleic) and 52\% (33.1\%-60.1\%) polyunsaturated (linoleic and linolenic) (Darla, 2003).

Gossypol is a toxic yellow polyphenolic compound produced by cotton and other members of the order Malvaceae,

*Corresponding author. E-mail: shaziz2408@yahoo.com such as okra (Jones, et. al., 1996). This colored compound is found in tiny glands in the seed, leaf, stem, tap root bark, and root of the cotton plant. The adaptive function of the compound is believed to be one of facilitating insect resistance. Further, gossypol acts as a male and female contraceptive. In addition, global cotton seed production can potentially provide the protein requirements for half a billion people per year. The three key steps of refining, bleaching and deodorization that are involved in producing finished oil act to reduce the gossypol level. Ferric chloride is often used to decolorize cotton seed oil (Yatsu et al.,2010).

Once processed, cotton seed oil has a mild taste and appears generally clear with a light golden color and the amount of color depends on the extent of refinement (Richard et al., 2005).

The cotton plant is a shrub native to tropical and subtropical regions around the world, including the Americas, Africa, and India. In Bangladesh the trees of Carpash, (silk cotton), the Gossypium herbaceum, which are found in almost every district of this country are slowly vanishing from the region. Carpash cotton is used for making good quality pillow, bed, 
and mattress. Gum of the plant and roots have some medicinal values (Richard et.al., 2005). Assuming normal monsoon condition, during the year 2011/12 cotton production in Bangladesh is forecast at 79,750 Bangladeshi bales (400 lbs) from 36000 hectares. A Carpash cotton tree can produce 50 $\mathrm{kg}$ of cotton and one $\mathrm{kg}$ cotton is sold at Tk 150 . One $\mathrm{kg}$ of cotton and waste cotton produces approximately $250 \mathrm{~g}$ of seed (Sarwar et al., 2011).

Though enormous work have been done on various activities of Gossypium herbaceum (Richard et al., 2005), no work has been reported in literature on the fatty acid composition of the cotton seed oil of Bangladesh (Gossypium herbaceum) and its physico chemical properties. Hence, the present study was carried out to: (a) estimate the chemical composition of the extracted cotton seed oil (b) quantify of fatty acid profile and (c) evaluate whether the oil can be used as edible purpose and other soap manufacturing purposes.

\section{Materials and Methods}

\section{Plant materials}

Different varieties of cottons are seen in Bangladesh. They are Shimul, Carpus, Akhondo etc. In this context Carpash (Gossypium herbaceum) seeds have been collected from Nilphamari, the district in Rajshahi, Bangladesh for the study of fatty acid composition and proximate analysis.

\section{Extraction}

The cottons along with seeds were cleaned to separate from dirt and grounded to obtain powder so that maximum particle exposure was got for extraction of oil. About $100 \mathrm{~g}$ of powder were extracted with ANALAR petroleum ether (b.p $40^{\circ} \mathrm{C}-60^{\circ} \mathrm{C}$ ) in a soxhlet apparatus for $72 \mathrm{~h}$. The extract was first filtered and then vacuum distilled to remove solvent completely. The color of the extracted oil was chocolate maroon. Then the extracted oil was filtered through ANALAR activated charcoal. Finally, light golden color of the oil was obtained. The yield of oil was calculated and stored in a refrigerator for further analysis (Anonymous,1984).

\section{Physicochemical study of the oil}

The physicochemical properties of the extracted oil were investigated with three replication as per cited standard methods (Anonymous, 1984; Anonymous, 2004; Kirk and Sarwer,1991) e.g. solubility, specific gravity, fatty oil(\%), acid value, Iodine value, saponification value.

\section{Identification and quantification of fatty acids}

The fatty acid contents (qualitative and quantitative) were determined by GLC of methyl esters. The fatty acid methyl esters (FAMEs) were prepared by complete esterification of oil using $\mathrm{BF}_{3}-\mathrm{MeOH}$ complex (Anonymous, 1984; Metacalfe et al., 1966: Bannon et.al., 1982.). Standard FAMEs (E.Merck) were used for the identification and quantification of the peaks.

For methylation, the lipid was first saponified with alcoholic sodium hydroxide, then cooled and diluted with water. After evaporation of alcohol, the acidified aqueous mixture was extracted with ether. Ether was then removed from ethereal solution to obtain fatty acid mixture. The fatty acid mixture was esterified with $\mathrm{BF}_{3}-\mathrm{MeOH}$ complex. After esterification, the reaction mixture was dissolved in diethyl ether in a separating funnel and was washed with dilute sodium carbonate solution until the effervescence was ceased. It was then washed with water, dried over anhydrous sodium sulphate and finally ether was removed to get methyl ester mixture (Anonymous, 1984; Metacalfe et al., 1966: Bannon et al., 1982.).

\section{Instrument and separation conditions}

The FAMEs were analyzed on a trace GC ULTRA, thermo electron Corporation, Gas Chromatograph fitted with a flame ionization detector and an electronic integrator. An SE-54 quartz capillary column $(30 \mathrm{mx} 0.25 \mathrm{~mm}$ i.d. and 0.25 $\mu \mathrm{m}$ film thicknesses) packed with $10 \%$ diethylene glycol succinate on 100-200 mesh solid support was used. Nitrogen gas used as a carrier gas at a flow rate of $1.5 \mathrm{~mL} / \mathrm{min}$. The separation was affected at $100{ }^{\circ} \mathrm{C}-220{ }^{\circ} \mathrm{C}$. The following temperature program was chosen in $\mathrm{GC}$ analyses; initial temperature $150{ }^{\circ} \mathrm{C}$, increasing at $7{ }^{\circ} \mathrm{C} / \mathrm{min}$ to $260{ }^{\circ} \mathrm{C}$ for $30 \mathrm{~min}$. The oven, injection and detection temperature were fixed at $150^{\circ}, 180^{\circ}, 220^{\circ} \mathrm{C}$ respectively. The fatty acid were identi- 
fied by comparison of relative retention times and peak positions of the chromatogram with those of the standard FAMEs. The amounts of fatty acid were calculated from the peak areas computed by LKB 2220 electronic recording integrator.

\section{Results and Discussion}

The results of the physicochemical properties and fatty acid composition of cotton seed oil are presented in Table I and II, respectively. Cotton seed oil contain $15.0 \%$ of fatty oil. higher fatty acids and also whether it contains high proportion of lower fatty acids or higher fatty acids. Saponification value was found within the range of (188.50-190.12) $\mathrm{mg}$, $\mathrm{KOH} / \mathrm{g}$, (Table I), indicating the presence of higher molecular weight fatty acids in oils. High molecular weight fatty acids are not good for human health. In that sense, fats or oils having low saponification number should be preferred (Meyer, 1987). The saponification values were quite similar with the range of olive oil (185-196), palm oil (200-205) mg, KOH/g. (Meyer, 1987; Lange, 1944; Mowla et. al., 1990; Ching, 2000; Jacobs, 2006; Nollet, 2004), representing typical $\mathrm{C}_{16}$ and $\mathrm{C}_{18}$ oils.

Table I: Physicochemical properties of Cotton (Gossypium herbaceum) seed oil

\begin{tabular}{lll}
\hline No. & Characteristics & Results \\
\hline 01. & Appearance & $\begin{array}{l}\text { A homogeneous ,opaque, almost liquid with light golden color and lighter } \\
\text { than water. }\end{array}$ \\
02. & Odor and teste & $\begin{array}{l}\text { Characteristic odor having mild but not pungent taste } \\
\text { Insoluble in water but freely miscible in chloroform, carbon tetrachloride, } \\
\text { pet ether, } \mathrm{n} \text {-hexane, diethylether and alcohol. }\end{array}$ \\
03. & Miscibility and solubility & $0.964 \pm 0.037$ \\
04. & Specific gravity at $30^{\circ} \mathrm{C}$ & 15.0 \\
05. & Fatty oil \% & $8.05 \pm 0.50$ \\
06. & Acid value (mg KOH/g) & $91.50 \pm 0.99$ \\
07. & Iodine value $(\mathrm{Hanus}$ method) & $28.90 \pm 0.30$ \\
08. & Peroxide value & $189.03 \pm 0.30$ \\
09. & Saponification Value (mg KOH/g) & $0.78 \pm 0.35$ \\
10. & Unsaponifiable matter(\%) & \\
\hline
\end{tabular}

* Each value represents the average of three replicate analyses \pm SD

Regarding physical properties, the oil is homogeneous, almost liquid and light golden color with a characteristics odor having mild but not pungent taste. It was freely miscible with chloroform, carbon tetrachloride, petroleum ether, n-hexane, diethyl ether and alcohol but immiscible with water.

Properties of the oil such as acid value, iodine value and saponification value usually give the structural, stability and quality information about the oils. Saponification value is the conversion of glycerol or ester into soap. The term is often used to describe the hydrolysis of any ester by alkali. The amount of alkali required to saponify a given amount of oil depends upon the molecular weight of the fatty acid present in the oil or fat (Mowla et. al., 1990). Saponification value tells whether the oil or fat contains lower proportion of
Iodine value is expressed in gm of iodine absorbed by 100 gms of oil or fat. It gives the indication of degree of unsaturation of the constituent oil and is thus a relative measure of the unsaturated bonds present in the oil (Mowla et. al., 1990). The iodine value is the characteristic of oil. One double bond absorbs one molecule of iodine. Unsaturated compounds absorbs iodine (in soluble form) and form saturated compounds. The extracted cotton seed fatty oil has the iodine value within (90.01-92.03) which were almost similar to those for olive oil (76-90) and sunflower oil (85-93) (Meyer,1987; Lange, 1944; Mowla et. al., 1990; Ching, 2000; Jacobs, 2006; Nollet, 2004). Iodine value increases as the degree of unstauration increases. So, the results indicate that the oil possesses high degree of unstauration. Therefore the extracted fatty oil possesses high proportion of higher unsaturated fatty acid. 
Table II: Fatty acid composition (in wt\%) of cotton (Gossypium herbaceum) seed oil of Bangladesh determined by GLC

\begin{tabular}{lccc}
\hline $\begin{array}{l}\text { Name of fatty } \\
\text { acids }\end{array}$ & $\begin{array}{c}\text { Retention } \\
\text { time/min }\end{array}$ & $\begin{array}{c}\text { Peak area } \\
\left(1 * \mathrm{uV}^{*} \mathrm{sec}\right)\end{array}$ & $\begin{array}{c}\text { Percent } \\
\text { composition }\end{array}$ \\
\hline Myristic acid $\mathrm{C}_{14: 0}$ & 16.40 & 22390 & 6.30 \\
Palmitic acid $\mathrm{C}_{16: 0}$ & 8.93 & 43993 & 11.73 \\
Stearic acid $\mathrm{C}_{18: 0}$ & 12.81 & 37133 & 9.90 \\
Oleic acid $\mathrm{C}_{18: 1}$ & 13.89 & 110244 & 29.40 \\
Linoleic acid $\mathrm{C}_{18: 2}$ & 23.38 & 49185 & 13.11 \\
Arachidic acid $\mathrm{C}_{20: 0}$ & 26.68 & 1250 & 0.10 \\
Ecosenoic acid $\mathrm{C}_{20: 1}$ & 20.12 & 3221 & 27.56 \\
\hline
\end{tabular}

Acid value denotes the number of $\mathrm{mg}$ of potassium hydroxide $(\mathrm{KOH})$ needed to neutralize the fatty acid in the oil or fat. The free fatty acid is produced by the hydrolytic decomposition of the oil. The low acid value is an indication of freshness of the oil .Acid values of cotton seed oil was found to vary from (7.0 to 9.05) indicating the proportion of free acid content was high than those in edible oil like soybean oil (0.38-0.54), mustard oil (3.65-4.5), coconut oil (4.0-4.5), seasame oil (4.0-6.0) (Meyer, 1987; Lange, 1944; Mowla et. al., 1990; Ching, 2000; Jacobs, 2006; Nollet, 2004). If the concentration of free fatty acid in a fat or oil is very high, then it is considered that the oil is hazardous for human health (Roy et. al., 2007). So now in this condition this oil cannot be used for edible purpose directly. But it can be used as edible oil after refining. Analar grade activated charcoal can be used for refining of cottonseed oil.

Peroxide value is the number of mili-equivalent of active oxygen, that expresses the amount of peroxide contained in $1000 \mathrm{~g}$ of the substance or peroxide oxygen per 1 kilogram of fat or oil. This value is a measurement of the extent to which rancidity reactions have occurred during storage. The double bonds found in fats or oils play a role in autoxidation. Oils with a high degree of unsaturation are most susceptible to autoxidation. The best test for autoxidation (oxidative rancidity) is the determination of the peroxide value. Autoxidation is a free radical reaction involving oxygen that leads to deterioration of fats and oils which form off flavors and off-order. The deterioted oil is hazardous for human health e.g. may cause of heart disease and also to promote the platelet stickness that leades to blood clot formation and may cause stomack problem etc (Richard et al., 2005).
Peroxide values of cotton seed oil was found within (28.9332.40). Peroxide value showed that the oil had much free active oxygen enabling autoxidation of the oil (Lange, 1944; Mowla et al., 1990; Jacobs, 2006).

Unsaponified matter contents (0.6-1.6) which is very much closer to some edible oils such as soybean oil $(0.2-1.5) \%$, sunflower oil ( $0.3-1.5) \%$, mustard oil ( $0.9-1.0) \%$ and olive oil $(0.5-1.5) \%$. Unsaponified matter includes those substances frequently found dissolved in fats and oils which cannot be saponified by caustic alkali but are soluble in ordinary fat solvents. This proportions varies between (0.5$2.0 \%$. So in this respect the cotton seed oil can be treated as edible oil (Mowla et. al., 1990; Jacobs, 2006; Nollet, 2004).

GLC analysis showed that oleic acid (29.40\%) was the major fatty acid found in the extract of cotton seed and the saturated fatty acids present in the oil sample were mainly palmitic acid (11.73\%), myristic acid (6.30\%) and stearic acid $(9.90 \%)$. Other unsaturated fatty acids were linoleic acid (13.11\%) and ecosenoic acid (27.56\%). The oleic acid percentage was comparable to those of corn oil (19-49)\%, grape seed oil (12-33)\%, mustard oil (20-22)\% and soyabean oil $(22-34) \%$. On the other hand the palmitic acid content was almost comparable to that in olive oil (7.0-20)\%. (Meyer, 1987; Lange, 1944; Mowla et. al., 1990; Ching, 2000; Jacobs, 2006; Nollet, 2004 ).

Healthful fats are lower in saturated and higher in monounsaturated fatty acid containing. A high oleic acid helps to reduce the raised level of total plasma cholesterol without reducing the high density lipoprotein (HDL) cholesterol level ( Francie et al., 1995).

In common vegetable oils usually contain (6-15)\% saturated fatty acids (Norton, 1989; Golfman and Bohme, 2001; Kamal Eldin and Yanishlieva, 2002) and cotton seed oil contains $29.40 \%$ saturated fatty acids of the total oil, so it is slightly higher in respect of the lower limit of the said percentage range due to presence of gossypol. Removing gossypol in the cottonseed oil can ,however, be treated as edible oil as its palmitic acid content is comparable to olive oil. Activated carbon can be used for refining of the oil. 


\section{Conclusion}

Demand of quality oils and fats is increasing all over the world. To cope with the increasing demand of the oils and fats the nonconventional sources are getting importance. The present investigation shows that the cotton seed contains $15 \%$ oil. Although a huge quantity of cotton waste and cotton seeds on total cotton production left unused in all over the world. The present investigation shows theses cotton seed oil can be a good source of edible oil (after refining). From the above investigation we can see the palmitic acid stearic acid and ecoseonic acid content is higher in the nonrefining oil so it can be used as a good source of toiletry and laundry soap. It can thus be concluded that the extracted oil can be treated as edible oil. In Bangladesh demand of edible oil is increasing so after refining these cotton seed oil can be used as edible oil and without refining theses oil can be used in soap manufacture industry.

\section{Acknowledgement}

Authors are thankful to the Director, Dhaka laboratories, Golam Rasul, Director, Bangladesh Cotton Development Board, S. M. Masud Karim (M. S. Student from Jagannath University), Mosarraf Hossain, (Jr.Tech.) CRD BCSIR Laboratories, Dhaka

\section{References}

A manual of laboratory techniques (1976). (National institute of nutrition, Indian council of medical Research, Hyderabad, India), pp 16-19.

Anonymous, Sept, (2009). Reports on Gm canola, Australlian Department of Primary Industries, p.54.

Anonymous, British Pharmacopea (B.P). (2004). Package Ed. British Pharmacopea Commission (Stationery office books) IV(A): 248-250.

Anonymous, Official Methods of Analysis (1984). 14th Ed. (Association of Official Analytical Chemist. Sydney, Williams. Arlington, USA), pp 530-532.

Banon CD, Craske JD, Hai N T, Harper NL and O'Rourke KL (1982). Analysis of fatty acid methyl esters with high accuracy and reliability II. Methylation of oils and fats with boron trifluride-methanol. J. Chromatogor., 247: 63-70.

Ching KC (2000). Fatty acid in foods and their health Implications. 2nd Ed. (Marcel Dekker Inc. Publisher, New York, pp 209-238.

Coutinho FM (2002). Gossypol; a contraceptive for men. Contraception 65(4): 259-263.

Darla RD, May (2003). The chemical and functional properties of cotton seed oil as a deep-fat frying Medium $J$. Am. Oil Chem. Soc., 79 (3):531-537.

Francie GD, Pamela JW, Linda MP and Thomas JB 1995. Fatty acid composition of oil from exotic corn breeding materials. J. Am. Oil Chem. Soc., 72(9): 981-987.

Jacobs MB (2006). The Chemical Analysis of Food Products. 3rd Ed., (CBS Publ.) pp 365-383.

Jones L, King A and Clay C (1996). "Cottonseed oil". In Y. H. Hui (ed.). Bailey's Industrial Oil and Fat Products, Edible Oil and Fat Products: Oils and Oilseeds. New York: Wiley. ISBN 978-0-471-59426-0.

Kirk SR and Sawyer RP (1991). Composition and Analysis of Foods. 9th Ed. (Longman, Scientific and Technical Press, Essen. UK), pp 617-620.

Lange NA. (1944). Handbook of Chemistry, 14th Ed. (Hand book Publishers Inc., Sandusky, Ohio), pp 678.

Metcafe LD, Schmitz AA and Pelka JR (1966). Rapid preparation of fatty acid esters from lipid for gas chromatographic analysis. Anal. Chem., 38: 514-515.

Meyer LH (1987). Food Chemistry 1st Ed. (CBS Publ. and Distr., Delhi, India), pp 12-64.

Mowla G, Sheick NM. and Kamal ASM (1990). Hand Book on Edible Oils and Fats with Special Reference to Bangladesh, 1st Ed. (University of Dhaka, Dhaka, Bangladesh), pp 9-172.

NCPA (2010). National Cotton Seed Products Association, 29 Nov. 
Nollet LM (2004). Hand book of Food analysis, Physical Characterization and Nutrient Analysis (Food Science and Technology) 2nd Ed. Vol-1. (Marcel Dekker Inc. Publishers, New York, USA)pp-221-274.

Norton G (1989). Nature and Biosynthesis of Storage Protams,, in Oil Crops of the World. G. Robbenlen; R. K. Downey and A. Ashri Ed. (McGraw-Hill: New York)pp 165-191.

Richard D, Brien. O', Lynn A, Jones C, Clay K, Philip J, Wakelyn, Peter J Wan (2005). Bailey's Industrial oil and fat products, 6th addition, Volume1 ,pp 173-274.
Roy SK and Saleh-E-In MM (2007). Studies of Fatty Acid Composition and Proximate Analysis of Anethum Sowa L. (Dill) Seed. Bang. J. Sci. Ind. Res., 42(4):455464.

Sarwer SH (2011). Bangladesh Cotton and Products Annual On Gain Report, 25-Apr.

Yatsu LY, Jacks TJ and Henserling T (2003). J. Am. Oil Chem. Soc., 47: No.2,73-74 DOI: 10,1007/BFO 254 1462.

Received: 09 January 2012; Revised: 26 January 2012; Accepted:10 February 2012. 